\title{
Erratum to: Freedom and Happiness in Nations: A Research Synthesis
}

\author{
Amanina Abdur Rahman ${ }^{1} \cdot$ Ruut Veenhoven $^{2,3}$
}

Published online: 29 August 2017

(C) Springer Science+Business Media B.V. and The International Society for Quality-of-Life Studies

(ISQOLS) 2017

\section{Erratum to: Applied Research Quality Life DOI 10.1007/s11482-017-9543-6}

The original version of this article, unfortunately, contained errors.

First, the hyperlinks found in body of Tables 2, 3, and 4 were omitted. The correct tables are now given in this article.

Second, the captions of Figures 2 and 3 were interchanged. The correct captions are:

Fig. 2 Relationship between freedom and happiness

Fig. 3 Example of a findings page in the World Database of Happiness

Third, hyperlinks to findings pages on the World Database of Happiness included in the text (page 11) were omitted. The pages are:

\section{Section N04: Happiness and Condition in One's Nation}

Section N04a0: Freedom and Happiness in nations

The original article has been corrected.

The online version of the original article can be found at http://dx.doi.org/10.1007/s11482-017-9543-6

\section{Amanina Abdur Rahman}

amanina.abdur.rahman@monash.edu

Ruut Veenhoven

veenhoven@ese.eur.nl

1 Department of Economics, School of Business, Monash University Malaysia, Jalan Lagoon Selatan, Bandar Sunway, 47500 Subang Jaya, Selangor, Malaysia

2 Erasmus Happiness Economics Research Organization (EHERO), Erasmus University Rotterdam, P.O. Box 1738, 3000 DR Rotterdam, The Netherlands

3 Opentia Research Program, North-West University, Vanderbijlpark, South Africa 
Table 2 Associations between freedom and happiness in nations

\begin{tabular}{|c|c|c|}
\hline Type of freedom & Zero-order & Partial \\
\hline \multicolumn{3}{|l|}{ Actual freedom } \\
\hline \multicolumn{3}{|l|}{ Opportunity to choose } \\
\hline Economic freedom & $+/+++++$ & $\begin{array}{l}+/+-+++/++/++ \\
+\end{array}$ \\
\hline Political freedom & $-/+/+++-+++$ & $\begin{array}{l}-/+/++-+/++/++ \\
-/-/++\end{array}$ \\
\hline Personal freedom & $-/+/++$ & $-/+$ \\
\hline Combined measurements & $+/+-/+/+$ & $+-/+$ \\
\hline \multicolumn{3}{|l|}{ Capability to choose } \\
\hline Awareness of alternatives & $\begin{array}{l}-/+/+++++ \\
-/+/++\end{array}$ & $-/++-/-/+$ \\
\hline Inclination to choose & $\begin{array}{l}---/+/+--+++ \\
++/+\end{array}$ & +++ \\
\hline $\begin{array}{l}\text { Combined measurements } \\
\text { (capability to choose) }\end{array}$ & $-/+/+$ & $-1+$ \\
\hline $\begin{array}{l}\text { Combined measurements } \\
\text { (opportunity }+ \text { capability to choose) }\end{array}$ & $+/+$ & + \\
\hline \multicolumn{3}{|l|}{ Attitudes towards freedom } \\
\hline Perceived freedom & + & \\
\hline Satisfaction with freedom & & $+/+$ \\
\hline Valuation of freedom & & \\
\hline
\end{tabular}

Positive associations are indicated with a plus sign (+), while negative associations are indicated with a minus sign $(-)$. Statistically significant associations at the $5 \%$ level are indicated by bolded plus and minus signs. Several signs in a string, such as $-/-/+/+$ indicate different findings from the same publication. 
Table 3 Associations between freedom and happiness by wealth of nations

\begin{tabular}{|c|c|c|}
\hline Type of freedom & Poor nations & Wealthy nations \\
\hline \multicolumn{3}{|l|}{ Actual freedom } \\
\hline \multicolumn{3}{|l|}{ Opportunity to choose } \\
\hline Economic freedom & $+/+++$ & -+++ \\
\hline Political freedom & ++ & ++++ \\
\hline Personal freedom & - & + \\
\hline Combined measurements (lack of inhibition) & -+ & ++ \\
\hline \multicolumn{3}{|l|}{ Capability to choose } \\
\hline Awareness of alternatives & +- & ++ \\
\hline Inclination to choose & -+ & ++ \\
\hline $\begin{array}{l}\text { Combined measurements } \\
\text { (capability to choose) }\end{array}$ & + & + \\
\hline $\begin{array}{l}\text { Combined measurements } \\
\text { (opportunity + capability to choose) }\end{array}$ & + & + \\
\hline \multicolumn{3}{|l|}{ Combined measurements } \\
\hline \multicolumn{3}{|l|}{ Attitudes towards freedom } \\
\hline \multicolumn{3}{|l|}{ Perceived freedom } \\
\hline \multicolumn{3}{|l|}{ Satisfaction with freedom } \\
\hline Valuation of freedom & & \\
\hline
\end{tabular}

Positive associations are indicated with a plus sign (+), while negative associations are indicated with a minus sign (-). Statistically significant associations at the $5 \%$ level are indicated by bolded plus and minus signs. Several signs in a string, such as $-/-/+/+$ indicate different findings from the same publication.

Table 4 Associations between freedom and happiness by the level of freedom in the country

\begin{tabular}{lll}
\hline Type of freedom & Low freedom & High freedom \\
\hline Actual freedom & & \\
$\quad$ Opportunity to choose & ++ & ++ \\
$\quad$ Economic freedom & -+ & ++ \\
$\quad$ Political freedom & - & ++ \\
$\quad$ Personal freedom & -+ & ++ \\
$\quad$ Combined measurements (lack of inhibition) & - & + \\
Capability to choose & - & $+/+$ \\
$\quad$ Awareness of alternatives & & \\
$\quad$ Inclination to choose & & + \\
$\quad$ Combined measurements (capability to choose) & & + \\
Attitudes towards freedom & + & \\
Perceived freedom & & \\
Satisfaction with freedom & & \\
Valuation of freedom &
\end{tabular}

Positive associations are indicated with a plus sign (+), while negative associations are indicated with a minus sign (-). Statistically significant associations at the $5 \%$ level are indicated by bolded plus and minus signs. Several signs in a string, such as $-/-/+/+$ indicate different findings from the same publication. 